\title{
Identifying factors which enhance capacity to engage in clinical education among podiatry practitioners: an action research project
}

Sally Abey ${ }^{1 *}$, Susan Lea ${ }^{2}$, Lynne Callaghan ${ }^{3}$, Steve Shaw ${ }^{4}$ and Debbie Cotton ${ }^{5}$

\begin{abstract}
Background: Health profession students develop practical skills whilst integrating theory with practice in a real world environment as an important component of their training. Research in the area of practice placements has identified challenges and barriers to the delivery of effective placement learning. However, there has been little research in podiatry and the question of which factors impact upon clinical educators' capacity to engage with the role remains an under-researched area. This paper presents the second phase of an action research project designed to determine the factors that impact upon clinical educators' capacity to engage with the mentorship role.

Methods: An online survey was developed and podiatry clinical educators recruited through National Health Service (NHS) Trusts. The survey included socio-demographic items, and questions relating to the factors identified as possible variables influencing clinical educator capacity; the latter was assessed using the 'Clinical Educator Capacity to Engage' scale (CECE). Descriptive statistics were used to explore demographic data whilst the relationship between the CECE and socio-demographic factors were examined using inferential statistics in relation to academic profile, career profile and organisation of the placement.
\end{abstract}

Results: The survey response rate was $42 \%(n=66)$. Multiple linear regression identified four independent variables which explain a significant proportion of the variability of the dependent variable, 'capacity to engage with clinical education', with an adjusted $R_{2}$ of 0.428 . The four variables were: protected mentorship time, clinical educator relationship with university, sign-off responsibility, and volunteer status.

Conclusion: The identification of factors that impact upon clinical educators' capacity to engage in mentoring of students has relevance for strategic planning and policy-making with the emphasis upon capacity-building at an individual level, so that the key attitudes and characteristics that are linked with good clinical supervision are preserved.

Keywords: Capacity building, Professional education, Podiatry, Psychometrics, Questionnaires

\section{Background}

Placement and work-based learning is of increasing importance in higher education as students build practical skills alongside their academic learning [1]. In the United Kingdom (UK), effective clinical education of healthcare professionals is facilitated through formal collaborations between the National Health Service (NHS) and higher education institutions, and students can

\footnotetext{
* Correspondence: sally.abey@plymouth.ac.uk

'Faculty of Health and Human Sciences, Plymouth University, Plymouth, UK Full list of author information is available at the end of the article
}

spend up to half of their programme of study on placement. A key factor in placement success is the role of the clinical educator. The clinical educator can make a difference between a supportive placement in which learning is maximised and one in which the student becomes disengaged and potentially fails to achieve learning outcomes [2-4]. While the term 'clinical educator' is generally ill-defined in the literature, in this study the role is seen as similar to that of the 'nursing mentor' (UK Nursing and Midwifery Council) who supports learning and assessment in practice across a range of 
domains [5]. In recent years, the responsibilities of the clinical educator have increased considerably $[2,6]$ while student numbers have also increased [7] and the focus on quality has sharpened $[8,9]$.

A range of factors has been shown to impact the student placement experience. These include the level of student preparation for placement; appropriate induction to the placement environment [10]; student numbers [11]; clinical educator's self-efficacy [10]; and the complexities of the clinical environment, including the clinical educator-student relationship [12]. Despite the importance of the clinical educator relatively little research has examined the factors associated with clinical educators' engagement with the role. In nursing, studies have shown that mentorship, enthusiasm for the nursing profession and collegiality are important [13]. Research has also identified universities provision of support to the placement area [14, 15], clinical educators obtaining a positive view of students [6] and protected time for mentoring [13] as influential factors.

Recently, research in the UK and Australia has started to focus on how increased numbers of students can be facilitated to undertake practice placement opportunities (a focus on organisational 'capacity' $[8,16-22])$, driven by changing workforce requirements [23-25], including the need to train more healthcare professionals, particularly nurses, as clinical educators $[7,11,26]$. There are many restrictions on capacity [23, 24], with clear tensions between increasing capacity and the provision of high quality placements [27] and patient care [11].

Research on capacity to date has focused largely on nursing and midwifery, and limited to staff perceptions of clinical education, specifically the negotiation of student numbers. The authors argue for the need to redefine and broaden the concept of capacity in healthcare clinical education. This definition includes building the capacity of significant individuals, groups and organisations to provide sustainable clinical education within the placement environment [28]. A multi-factorial concept, capacity-building requires a whole system approach to understand and support the complex structures which underpin the increase in students allocated to the placement setting. The clinical educator plays a critical part in facilitating students within the clinical environment and their capacity to undertake the role and manage the learning environment requires support and development. Building capacity in this context involves an on-going process which empowers the organisation, and the groups and individuals within it [28] to achieve the objective of effective, high quality placement learning. It is therefore essential to examine the role of the clinical educator within this whole system approach.
The 'Clinical Educator Capacity to Engage' scale (CECE) was developed by the authors [17] to identify the variables that predict podiatry clinical educator capacity to engage with the role of mentorship. The 74-item CECE scale comprises nine sub-scales (anxiety; confidence; culture; job satisfaction; leadership; management; support; positive attitude towards the role of clinical educator; negative attitude towards the role of clinical educator) and has been shown to have good reliability [17]. Establishing the factors that impact upon clinical educator capacity may identify opportunities for placement planning, organisation and support, resulting in more effective practice placement. The aim of the research was to survey podiatry clinical educators to explore factors thought to predict the variability of clinical educator capacity to engage in the mentorship role.

\section{Method}

This research represents part of a larger collaborative action research project between one higher education institute and an NHS podiatry department. An action research approach allowed for the exploration of the complex issues that surround placement learning whilst taking a collaborative approach with stakeholders [29]. The framework supports a systematic approach to problem-solving [30] where issues/challenges/barriers are 'analysed/diagnosed', which leads to the formulation of an 'action plan' which addresses issues and changes practice (see Fig. 1). The action can subsequently be evaluated by the whole action research team and is a powerful way of informing practice where mixed methodological approaches to research may be applied [31].

\section{Action research team}

The stakeholders forming the action research team comprised clinical educators from podiatry and nursing. These stakeholders discussed the barriers and challenges to clinical education and provided a multi-lens perspective of this complex environment. The initial 'diagnosis phase' (cycle one) had established that the team held positive attitudes towards the clinical educator role and regarded it as an integral part of their professional responsibility as a healthcare professional. From these discussions, the construct 'capacity to engage' was generated and broadly defined. The Action Research Team (ART) felt the clinical educators' capacity to engage with clinical education was high, but a lack of empirical research meant that this belief could not be substantiated.

\section{Capacity to engage with clinical education scale}

During the planning phase the ART and SA, SL and LC developed an instrument for measuring Clinical Educators' Capacity to Engage with the mentorship role, the 


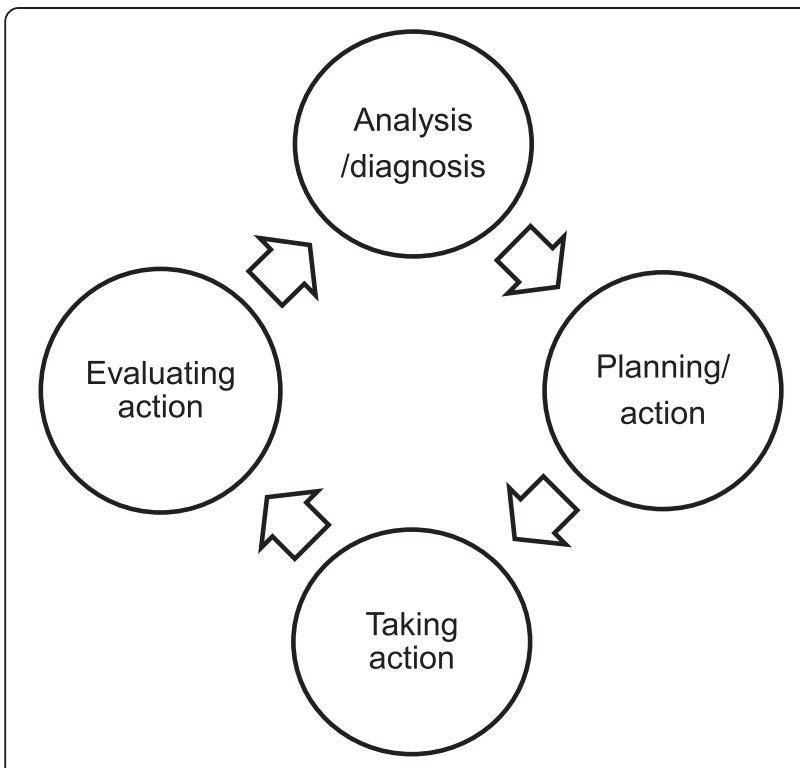

Fig. 1 Spiral of action research cycles adapted from Coghlan and Brannick [29]

CECE scale [23], consisting of 74 items within nine subscales: anxiety; confidence; culture; job satisfaction; leadership; management; support; positive attitude towards the role of clinical educator; negative attitude towards the role of clinical educator.

The scale has subsequently been found to have good to excellent reliability (Cronbach's alpha 0.782 to 0.951 ) following the piloting with podiatry clinical educators within 25 English NHS Trusts. The development and piloting of the scale was an important first step to ascertaining reliability.

\section{Workshop 1: Research model and independent variables}

The ART initially met with SA to discuss the development of the scale alongside identifying the potential factors that might impact upon an individual's capacity to engage with clinical education. As part of the discussion, factors (variables) that were thought to impact upon this capacity were identified from the considerable combined pedagogical experience of the clinical educators within the team, alongside nursing and midwifery literature. These predictive factors were reworked into hypotheses that could then be tested against the CECE scale (see Fig. 2). The independent variables that were identified as potentially influential were socio-demographic factors, academic profile, career profile, and placement organisation.

\section{Ethics}

Ethical approval was granted by the Cornwall \& Plymouth Research Ethics Committee (09/H0203/95) as well as the Plymouth University Ethics Committee.

\section{Data collection}

\section{Recruitment}

Heads of service in 15 podiatry departments were sent a letter inviting staff who act as clinical educators to participate in the research. Postcards were included which advertised the research and offered potential participants the opportunity to win one of two $£ 25$ book vouchers on completion of the survey. Participant anonymity was assured, although an email address was requested if individuals wished to be entered into the prize draw; this was administered by an independent third party.

\section{Materials}

The survey was hosted online and heads of service were asked to engage their staff in the research by forwarding the postcard to them. The survey was live for a six-week period and at two weekly intervals reminder emails were issued.

\section{The Sample}

The population for the research comprised all podiatrists with clinical educator responsibilities, regularly or on an ad hoc basis, for the BSc (Hons) Podiatry programme at one UK University.

\section{Data analysis}

All analysis was undertaken using PASW $^{\oplus}$ version 18. Descriptive statistics were used to examine demographic data. The relationship between the CECE scale and socio-demographic factors, academic profile, career profile, and placement organisation was examined. Analysis was restricted to the use of non-parametric tests where the data were ordinal and nominal in nature. Inferential statistics were used, specifically the Mann-Whitney U and Kruskal-Wallis tests leading to multiple linear regression. Individual factors were explored and those that were significant informed a regression which sought to identify a model of clinical educator capacity. A significance level of 0.05 was set (See Table 1) with an adjustment of the p-value threshold to $<0.1$ as stated in Table 2. Assumptions of linearity and homoscedasticity were met overall in relation to the multiple linear regression [30].

\section{Results}

\section{Response rate}

The response rate was $42 \%(n=66)$ from an estimated 158 clinical educators. Of the 66 respondents to the survey $23 \%(n=15)$ were male and $77 \%(n=50)$ were female (one unknown). This ratio of approximately 1:3 (male: female) reflects the professional trend (Health and Care Professions Council 2012; personal email). Of the 66 respondents, $18 \%(n=12)$ were between 20 to 29 , 


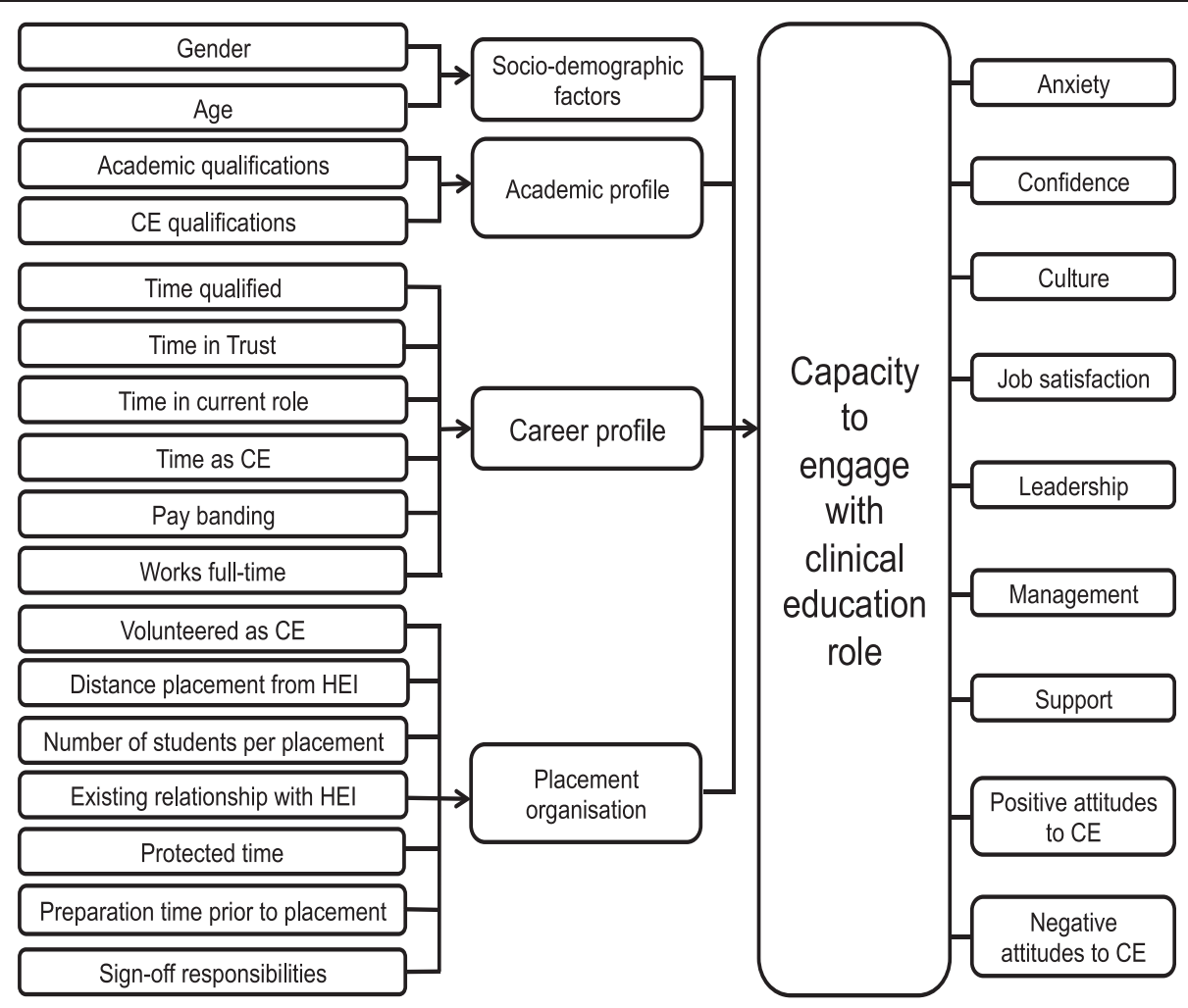

Fig. 2 Independent variables shown in relation to dependent variable: Capacity to engage with the role of clinical education

$24 \%(n=16)$ between 30 to $39,32 \%(n=21)$ between 40 to 49 and $26 \%(n=17)$ between 50 to 59 years of age.

\section{Hypotheses testing}

Statistical tests were conducted to test hypotheses relating to factors associated with podiatrists' capacity to engage in clinical education. A number of significant results were obtained and are detailed in Table 1 . Increased capacity to engage in clinical education was found to be associated with clinical educators volunteering for the role (Mann-Whitney $\mathrm{U}$ test, $p=0.003$ ); full-time employment of the clinical educator (Mann-Whitney U test, $p=0.010)$; time being allocated to the clinical educator for preparation in advance of the student joining the placement (Mann-Whitney $\mathrm{U}$ test, $p=0.002$ ); protected time for clinical education within the working day but outside clinical hours (Mann-Whitney U test, $p=0.002$ ); mentors having a number of students, rather than a single student,

Table 1 Factors associated with podiatrists' capacity to engage in clinical education

\begin{tabular}{|c|c|c|c|c|}
\hline Factor & Statistical test & $\mathrm{N}$ & Results & Significance \\
\hline Participants who volunteer as clinical educators demonstrate greater capacity to engage & Mann-Whitney U & 66 & $U=306.0$ & $p=0.003$ \\
\hline $\begin{array}{l}\text { A relationship with the university, outside the clinical educator role (e.g. previous student) will } \\
\text { produce greater capacity to engage in the role }\end{array}$ & Mann-Whitney U & 65 & $U=253.5$ & $p=0.099^{*}$ \\
\hline Clinical educators' engagement with the role increases when employed full-time & Mann-Whitney U & 60 & $U=260.5$ & $p=0.010$ \\
\hline Preparation time prior to student attendance on placement would increase capacity to engage & Mann-Whitney U & 59 & $U=132.5$ & $p=0.002$ \\
\hline $\begin{array}{l}\text { Where protected time outside clinical hours was timetabled the hypothesis stated that capacity } \\
\text { to engage would be higher }\end{array}$ & Mann-Whitney U & 59 & $U=115.0$ & $p=0.002$ \\
\hline $\begin{array}{l}\text { Clinical educators with only a single student to mentor per placement would show greater } \\
\text { capacity for engagement }\end{array}$ & Mann-Whitney U & 66 & $U=361.5$ & $p=0.037$ \\
\hline $\begin{array}{l}\text { Responsibility for signing-off students' learning outcomes would impact positively on clinical } \\
\text { educators' capacity to engage }\end{array}$ & Mann-Whitney U & 65 & $U=248.0$ & $p=0.006$ \\
\hline $\begin{array}{l}\text { Where clinical educators' employment was closer to the university capacity scores would be higher. } \\
\text { Five distance categories were established: } 0 \text { to } 49 \text { miles; } 50 \text { to } 99 \text { miles; } 100 \text { to } 149 \text { miles; } 150 \text { to } \\
199 \text { miles; } 200 \text { to } 249 \text { miles }\end{array}$ & Kruskal-Wallis & 65 & $H(4)=8.78$ & $p=0.067^{*}$ \\
\hline
\end{tabular}


Table 2 Factors not associated with podiatrists' capacity to engage in clinical education

\begin{tabular}{|c|c|c|c|c|}
\hline Factors & Statistical test & $\mathrm{N}$ & Results & Significance \\
\hline $\begin{array}{l}\text { The length of time a clinical educator has been qualified as a podiatrist will results in higher } \\
\text { capacity to engage scores }\end{array}$ & Spearman's rho & 65 & $r_{s}=0.119$ & $p=0.346$ \\
\hline $\begin{array}{l}\text { The length of time a clinical educator has worked for a particular NHS Trust will result in } \\
\text { higher capacity to engage scores }\end{array}$ & Spearman's rho & 66 & $r_{s}=0.173$ & $p=0.165$ \\
\hline $\begin{array}{l}\text { The length of time a clinical educator has worked in a particular role will result in higher } \\
\text { capacity to engage scores }\end{array}$ & Spearman's rho & 65 & $r_{s}=0.073$ & $p=0.562$ \\
\hline $\begin{array}{l}\text { The length of time a clinical educator has undertaken the mentoring role will result in higher } \\
\text { capacity to engage scores }\end{array}$ & Spearman's rho & 64 & $r_{s}=0.051$ & $p=0.690$ \\
\hline Higher levels of banding will result in higher capacity to engage scores & Kruskal-Wallis test & 66 & $H(3)=1.55$ & $p=0.671$ \\
\hline The level of academic qualification will affect capacity to engage scores & Kruskal-Wallis test & 65 & $H(4)=4.97$ & $p=0.290$ \\
\hline \multirow[t]{2}{*}{ Attainment of clinical educator training will impact on capacity to engage scores } & Kruskal-Wallis test & 66 & $H(4)=1.34$ & $p=0.855$ \\
\hline & Mann-Whitney U & 66 & $U=485.50$ & $p=0.796$ \\
\hline
\end{tabular}

to mentor (Mann-Whitney U Test, $p=0.037$ ); responsibility to sign off students' learning outcomes (Mann-Whitney $\mathrm{U}$ test, $p=0.006$ ); having a relationship with the university outside the clinical educator role, such as having been a student there previously (Mann-Whitney U test, $p \leq 0.05$ ); and proximity of the placement to the university (KruskalWallis test, $p \leq 0.05$ ).

A prior relationship with the University and the distance from the University both approached significance and to explore whether either had any potential explanatory value in predicting clinical educator capacity to engage with the role within the regression model the significance level was raised to $p \leq 0.1$. Ten Mann-Whitney $U$ tests were performed for each category resulting in ten paired independent samples. The significance level was relaxed and set at $p \leq 0.1$ and the results were significant for four of the paired independent samples; 0 to 49 miles and 50 to 99 miles $(p<0.046) ; 0$ to 49 miles and 100 to 149 miles $(p<0.046) ; 0$ to 49 miles and 150 to 199 miles $(p<0.096) ; 0$ to 49 miles and 200 to 249 miles $(p<0.063)$. Although, the results for distance from the university were not all significant at $p \leq 0.05$ they were at $p \leq 0.1$ and these four variables were included within the regression analysis in order to determine whether they had any explanatory value for predicting capacity to engage with clinical education within the regression model.

\section{Multiple linear regression}

In total eleven variables were considered within the initial regression, subsequently producing a model comprised of four variables. Initially, the variables were considered together which led to the identification of one variable that was best able to predict the outcome based on levels of significance. The chosen variable was then retained within the model and a second predictor variable was subsequently identified. This process was repeated until all the variables had been either included or excluded from the regression model. This enabled the generation of a model to ascertain the extent to which the variables identified from the initial analysis were predictive of the variability of the dependent variable, 'clinical educator capacity to engage in the mentorship role'. The results are presented in Table 3. The regression model summary produced was as follows: $R_{2} 0.428$ $(p<0.001)$.

The four independent variables identified (protected mentorship time, clinical educator relationship with university, sign-off responsibilities and volunteer status of

Table 3 Multiple regression to identify predictors of podiatrists' capacity to engage in clinical education

\begin{tabular}{|c|c|c|c|}
\hline & B & SE.B & $\beta$ \\
\hline \multicolumn{4}{|l|}{ Step 1} \\
\hline Constant & 247.96 & 4.08 & \\
\hline Protected mentorship time & 31.48 & 9.00 & $0.42^{*}$ \\
\hline \multicolumn{4}{|l|}{ Step 2} \\
\hline Constant & 242.28 & 4.21 & \\
\hline Protected mentorship time & 32.80 & 8.36 & $0.44^{* *}$ \\
\hline Clinical educator relationship with university & 26.10 & 8.36 & $0.35^{* *}$ \\
\hline \multicolumn{4}{|l|}{ Step 3} \\
\hline Constant & 227.96 & 6.13 & \\
\hline Protected mentorship time & 27.01 & 8.01 & $0.36^{* *}$ \\
\hline Clinical educator relationship with university & 26.91 & 7.80 & $0.36^{* *}$ \\
\hline Sign-off responsibilities & 21.70 & 7.13 & $0.33^{* *}$ \\
\hline \multicolumn{4}{|l|}{ Step 4} \\
\hline Constant & 221.47 & 6.40 & \\
\hline Protected mentorship time & 25.52 & 7.67 & $0.34^{* *}$ \\
\hline Clinical educator relationship with university & 27.71 & 7.45 & $0.37^{* *}$ \\
\hline Sign-off responsibilities & 19.00 & 6.89 & $0.29^{* *}$ \\
\hline Volunteer status of clinical educator & 15.51 & 6.18 & $0.25^{* *}$ \\
\hline
\end{tabular}

Note: Adjusted $R_{2}=0.17$ for Step $1{ }^{*} p \leq 0.001$, adjusted $R_{2}=0.28$ for step 2, adjusted $R_{2}=0.37$ for step 3, adjusted $R_{2}=0.43$ for step 4 . ${ }^{*} p<0.001$ 
clinical educator) represent $43 \%$ of the predictive variability of the dependent variable - capacity to engage in clinical education.

\section{Discussion}

This research aimed to identify the factors that impact upon clinical educators' capacity to engage in the role in the context of podiatry. Findings revealed factors which increase the capacity of clinical educators in this role to include: being provided with protected time to engage in preparation and support of students; having a current or previous relationship with the university which goes beyond the clinical educator role; having assessment and sign-off responsibilities for students; and volunteering for the role. In addition to identifying individual factors which influence the capacity of clinical educators to engage in the role, the research produced a model capable of predicting individual clinical educators' performance in relation to capacity to engage. The model accounts for $43 \%$ of the predictive variability of capacity of clinical educators to engage with the role and, therefore, has utility in identifying opportunities for placement planning, organisation and support - resulting in more effective practice placement.

The findings of this study are supportive of Jokelainen et al. [13] who found protected time to be valued by clinical educators. The mentorship role is a major responsibility for the clinical educator both in terms of the student's placement experience and their progression within the clinical environment. Ideally time should be embedded within the timetable for the clinical educator and student, outside the podiatrist's clinical responsibilities, to engage with mentoring. This may include reflecting on the day's or week's events to contextualise experiences and reinforce theory, providing pastoral support and setting new goals and learning opportunities in partnership with the student.

This study has shown that where the clinical educator has a previous or existing relationship with the university, capacity for mentorship is increased. This result supports previous work where loyalty links have been established with a place of previous study or where endeavours which result in the attainment of an award are currently being undertaken [21]. This type of allegiance can be conceptualised as brand loyalty, with the University representing the brand. The students' relationship with 'using the brand' appears to create a sense of loyalty which extend to actions beyond graduation [32].

Where clinical educators undertake the responsibility for signing-off learning outcomes there was found to be an increase in capacity for the role [6]. Assessment of competency is integral to the role and often necessitates liaison with other clinical educators regarding their assessment of student capabilities conferring considerable extra responsibility to the clinical educator who will decide on students' ability to progress. The placement process may be more challenging for some students than for others, and ultimately be more rewarding for the clinical educator when a successful achievement of summative assessment is reached. Where clinical educators are not given this responsibility it may have a negative effect, with the clinical educator having spent time developing a student, but without recognition of this substantial investment.

Volunteering for the clinical educator role increased capacity scores. It would seem natural that individuals that choose to undertake a role are more likely to be well disposed towards it, as it is perhaps viewed as vocational rather than compulsory [32]. A requirement for an increase in placements allocations may result in staff having to take on these roles. This may be counter-productive as unwilling staff are unlikely to mentor students effectively, and may even impact on student attrition.

The insignificant results concerning the clinical educator's education and experience are surprising, especially given evidence in other professions of the importance of qualifications on student learning (e.g. Nasr et al. [33]. This finding may reflect the homogeneity of variance associated with the sample which may not be reflective of samples in previous research. It is possible that less experienced staff are better able to understand the perspective of students than their more experienced colleagues, thus they off-set a lack of experience with an increased enthusiasm for the role.

The CECE scale provides a useful tool to examine the engagement of clinical educators in students' learning. Further research using the scale with podiatrists both in the UK and internationally would provide important comparative data. The scale could also be adapted for use with other health professionals engaging in clinical education; this would be beneficial given the multiprofessional context within which both practitioners and students frequently work. Building the body of work involving the CECE would yield larger samples thereby enabling more sophisticated statistical analyses with greater power. Given that the CECE scale is self-report, it would be important for future research to also measure aspects of the clinical environment independently (e.g. the ratio of educators to students; clinical caseload; student feedback).

Further research to explore other factors that impact upon capacity to engage in the role of clinical educator is required which surveys all podiatrists who undertake clinical education. Other possible factors which affect capacity could be included, such as the total number of students mentored each year by an individual clinical educator, perhaps from other health professions or universities and possibly on an ad hoc basis. Factor and 
Rasch analysis with a larger number of respondents may then be possible, to further develop and validate the CECE scale. Further testing of the model would also be beneficial. The CECE scale could be adapted and utilised with other healthcare professionals, increasing the sample size and inclusive of an international perspective. There is also scope to include other dimensions in the CECE scale, such as clinical educators' perception of the responsibilities and ambit of the role. This work has the potential to provide guidance to the organisation and to inform the resourcing of healthcare students' placements more generally.

\section{Limitations}

While this research has contributed new knowledge in the area of podiatry training, the study suffers a number of limitations. First, the sample comprised of podiatrists from a single region of the UK, which limits the generalisability of the findings. Although the sample was drawn across both rural and urban placement contexts within a range of organisational environments of varying sizes, it is possible that regional variation may impact clinical education practice. Second, while the response rate to the survey was satisfactory, it is possible that nonrespondents may have differed from respondents in relation to characteristics that were relevant to capacity to engage. The research findings, therefore, need to be interpreted with some caution. As with much survey research of this nature, the study assessed the perceptions of clinicians as to the barriers and facilitators to their engagement with the clinical educator role. Such perceptions are important as they describe the lived experience of clinicians and will affect their practice. Nevertheless, perceptions are not necessarily accurate reflections of the external environment.

\section{Conclusions}

Establishing the factors that are significant in influencing capacity to undertake the role of clinical educator is crucial in the further support and development of placements in higher education. Capacity-building requires a sustainable approach with participation at an organisational, group and individual level, impacting upon management of placements at both a local and national level. This study has specifically focused on the individual, and on relationships between the university and practice setting. Commitment to investment of resources and opportunities is required, not only to increase individual capacity, but also to support quality and effectiveness of training opportunities. Enhancing clinical educator capacity for the role will promote the development of effective placements leading to the potential for increasing allocations and impacting positively upon attrition rates. At a practical level, this research informs podiatry placement recruitment to the role of clinical educator, which will promote engagement with the task. These findings are of relevance in relation to strategic planning, policy-making in the NHS and for the higher education institutions organising placements at a local level.

\section{Abbreviations}

ART: action research team; CECE: clinical educator capacity to engage; NHS: National Health Service; UK: United Kingdom.

\section{Competing interests}

There are no competing interests in relation to this research.

\section{Authors' contributions}

The principal author undertook this research as part of a larger action research project in pursuit of a $\mathrm{PhD}$ and therefore took the primary role in all aspects of the research. The director of studies, Professor Lea and second supervisor, Dr Callaghan were engaged in the design, development and analysis of the scale and contributed fully to the writing of the paper. Dr Shaw provided guidance and advice relating to the statistical analysis and Professor Cotton provided guidance around action research and reviewed the paper.

\section{Acknowledgements}

Funding was received from the Centre for Excellence in Professional Placement Learning, part of the Centres for Excellence in Teaching and Learning initiative of the Higher Education Funding Council for England. Approval for this project was granted by the Cornwall and Plymouth Research Ethics Committee and by the Ethics Committee of the University's Faculty of Health, Education \& Society and is in accordance with the Declaration of Helsinki. The anonymity of participants, those undertaking the survey and those that are members of the action research team, was guaranteed. Information sheets were issued and informed consent was obtained for the participants of the action research team.

The principal author would like to thank the members of the action research team for their valuable input to the project.

\section{Author details}

${ }^{1}$ Faculty of Health and Human Sciences, Plymouth University, Plymouth, UK. ${ }^{2}$ Deputy Vice-Chancellor (Academic), University of Greenwich, London, UK. ${ }^{3}$ Centre for Mental Health and Justice, Cornwall Partnership NHS Foundation Trust, Cornwall, UK. ${ }^{4}$ School of Computing and Mathematics, Plymouth University, Plymouth, UK. ${ }^{5}$ Pedagogic Research Institute and Observatory, Plymouth University, Plymouth, UK.

Received: 12 December 2014 Accepted: 14 November 2015 Published online: 26 November 2015

\section{References}

1. Lester S, Costley C. Work-based learning at Higher Education: value, practice and critique. Stud High Educ. 2010;35:561-75.

2. Jokelainen M, Turunen $H$, Tossavainen $K$, Jamookeeah D, Coco K. A systematic review of mentoring nursing students in clinical placements. J Clin Nurs. 2011;20:2854-67.

3. Ali PA, Panther W. Professional development and the role of mentorship. Nurs Stand. 2008;22:35-9.

4. Andrews M, Wallis M. Mentorship in nursing: a literature review. J Adv Nurs. 1999;29:201-7.

5. Nursing and Midwifery Council.Standards to Support Learning and Assessment in Practice. 2008. http://www.nmc-uk.org/Documents/ Standards/ nmcStandardstoSupportLearning\%20AndAssessmentInPractice2008.pdf

6. Myall M. Mentorship in contemporary practice: the experiences of nursing students and practice mentors. J Clin Nurs. 2008;17:1834-42.

7. Hutchings A, Williamson GR, Humphreys A. Supporting learners in clinical practice: capacity issues. J Clin Nurs. 2005;14:945-55.

8. European Association for Quality Assurance in Higher Education.Standards and Guidelines for Quality Assurance in the European Higher Education Area. 2005,1-41. 
9. Department of Health. Report to the National Allied Health Professional Advisory Board on the Outcomes of the Modernising Allied Health Professional Careers Programme. London: HMSO; 2011.

10. Rodger S, Fitzgerald C, Davila W, Millar F, Allison H. What makes a quality occupational therapy practice placement? Students' and practice educators' perspectives. Aust Occup Ther J. 2011;58:195-202.

11. Murray SC, Williamson GR. Managing capacity issues in clinical placements for pre-registration nurses. J Clin Nurs. 2009;18:3146-54.

12. Dunn SV, Hansford B. Undergraduate nursing students' perceptions of their clinical learning environment. J Adv Nurs. 1997;25:1299-306.

13. Jokelainen M, Jamookeeah D, Tossavainen K, Turunen H. Building organizational capacity for effective mentorship of pre-registration nursing students during placement learning: Finnish and British mentors' conceptions. Int J Nurs Pract. 2011;17:509-17.

14. Andrews $M$, Roberts $D$. Supporting student nurses learning in and through clinical practice: the role of the clinical guide. Nurse Educ Today. 2003;23:474-81.

15. O'Keefe M, Burgess T, McAllister S, Stupans I. Twelve tips for supporting student learning in multidisciplinary clinical placements. Med Teach. 2012;34:883-7.

16. Magnusson C, O'Driscoll M, Smith P. New roles to support practice learning can they facilitate expansion of placement capacity? Nurse Educ Today. 2007:27:643-50.

17. Abey S, Lea S, Callaghan L, Cotton D, Shaw S. The development of a scale to assess practitioner capacity to engage in clinical education. J Furth High Educ. 2013;1-18.

18. Pallant J. SPSS Survival Manual. Buckingham: Open University Press; 2001.

19. Kline A. The Handbook of Psychological Testing. 2nd ed. London: Routledge; 1999

20. Field A. Discovering Statistics Using SPSS. 3rd ed. London: Sage Publications Ltd; 2009.

21. McAlexander J, Koenig H. University experiences, the student-college relationship, and alumni support. J Mark High Educ. 2001;10:21-43.

22. McAlexander J, Koenig H, Schouten J. Building a university brand community: the long-term impact of shared experiences. J Mark High Educ. 2005;14:61-79

23. Barnett T, Cross M, Jacob E, Shahwan-Akl L, Welch A, Caldwell A, et al. Building capacity for the clinical placement of nursing students. Coll J R Coll Nurs Aust. 2008;15:55-61.

24. Courtney-Pratt H, FitzGerald M, Ford K, Marsden K, Marlow A. Quality clinical placements for undergraduate nursing students: a cross-sectional survey of undergraduates and supervising nurses. J Adv Nurs. 2012;68:1380-90.

25. Barnett T, Walker LE, Jacob E, Missen K, Cross MD, Shahwan-Akl L. Expanding the clinical placement capacity of rural hospitals in Australia: displacing Peta to place Paul? Nurse Educ Today. 2012;32:485-9.

26. Pease S, Kane S. The role of the nurse specialist. Nurs Stand. 2010;24:42-6.

27. Cox CE, Lindblad AJ. A collaborative approach to improving and expanding an experiential education program. Am J Pharm Educ. 2012;76:1-5.

28. Baillie E, Bjarnholt C, Gruber M, Hughes R. A capacity-building conceptual framework for public health nutrition practice. Public Health Nutr. 2008:12:1031-8.

29. Coghlan D, Brannick T. Doing Action Research in Your Own Organization. London: Sage Publications Ltd; 2005.

30. Pasmore W, Friedlander F. An action-research program for increasing employee involvement in problem solving. Adm Sci Q. 1982;27:343-62.

31. Barbour $\mathrm{R}$. The role of qualitative research in broadening the "evidence base" for clinical practice. J Eval Clin Pract. 2000;6:155-63.

32. Bennett R. Clinical education: perceived abilities/qualities of clinical educators and team supervision of students. Physiotherapy. 2003;89:432-42.

33. Nasr AR, Gillett M, Booth T.Do university teachers require qualifications in education?: An investigation of Lecturers. Res Dev High Educ. 1996;529-534.

\section{Submit your next manuscript to BioMed Central and we will help you at every step:}

- We accept pre-submission inquiries

- Our selector tool helps you to find the most relevant journal

- We provide round the clock customer support

- Convenient online submission

- Thorough peer review

- Inclusion in PubMed and all major indexing services

- Maximum visibility for your research

Submit your manuscript at www biomedcentral com/submit
() Biomed Central 